Рассмотренные результаты исследования еще раз показали, что компьютеризированное общение приводит к формированию, особенно у взрослеющего человека, качественно иных личностных характеристик, способов взаимодействия с другими людьми, представлений о ценности себя и другой личности (например, тенденция к доминированию и отсутствие интереса к опыту другого человека). Все это говорит о необходимости изучения вопросов становления личности в условиях усиливающегося воздействия компьютерных форм взаимодействия в структуре межличностных отношений юношей и девушек

На сегодняшний день можно с уверенностью констатировать, что условия развития и социализации личности молодого человека (подростка, юноши) очень сильно изменились: его взросление и становление как личности происходит в условиях активного включения в виртуальное общение, которое становится основным способом выстраивания межличностных отношений молодого человека, познания самого себя, личностного самоопределения и социального самоутверждения. Это требует научного изучения и переосмысления механизмов и процессов становления личности в юношеском возрасте

\title{
ВЛИЯНИЕ ИНДИВИДУАЛЬНО-ПСИХОЛОГИЧЕСКИХ ОСОБЕННОСТЕЙ ЛИЧНОСТИ НА ЕЁ КОНФОРМНОЕ ПОВЕДЕНИЕ В ПОДРОСТКОВОМ ВОЗРАСТЕ
}

Макарова И.Н.

В отдельных аспектах отечественной психологии традиционная основа рассмотрения некоторых психологических феноменов уже не всегда себя оправдывает, необходим новый, возможно интегративный подход к изучению этих феноменов. В поиске этих новых подходов и состоит одна из важнейших задач современных психологов. В данном исследовании нами была предпринята попытка найти такой новый подход к рассмотрению одного из центральных феноменов социального влияния - феномена конформности.

В самом начале работы над изучением данного социальнопсихологического феномена стояла задача глубокого анализа всех накопленных знаний о самом феномене конформности, о его детерминантах, о методах исследования и вообще обо всех его аспектах и проявлениях. Мы столкнулись с тем, что при всём многообразии накопленного учёными-психологами материала, касающегося проблематики социального влияния, у нас не сформировалось единого образа, дающего представление о проявлениях и взаимозависимостях различных аспектов феномена конформности в поведении человека. Существуют модели, представляющие психологический механизм отдельных аспектов конформности; глубоко и всесторонне изучены конформные тенденции в поведении отдельных профессиональных и возрастных групп; выявлено множество личностных и ситуационных факторов конформности, однако целостной картины феноменологии явления нет. Поэтому первой из задач нашей работы стало создание и исследование по 
возможности полного «образа» проявлений конформности в поведении человека и влияния на нее индивидуально-психологических особенностей личности именно в подростковом возрасте $[1,2]$.

С одной стороны, изучение всех проявлений конформности в целостности и многообразии без сомнения является чертой гуманистического подхода в психологии. С другой стороны, использование эксперимента и математических средств анализа результатов принадлежат позитивистской ориентации. Однако, на наш взгляд, на сегодняшний день именно интеграция лучших достижений всех направлений является необходимым условием дальнейшего развития психологии как науки.

Необходимо отметить, что все исследования проводились не в лабораторных, а в реальных малых группах, поэтому полученные результаты касаются описанной нами внутригрупповой конформности, отличающейся, по нашему мнению, от конформности, проявляемой испытуемыми в лабораторных группах (конформности диффузных групп).

Эмпирическое исследование описанного нами (многообразия) континуума подтвердило выдвинутую нами гипотезу о том, что конформность может быть описана не как полярное явление конформизм-нонконформизм, а как многообразие (континуум) в разной степени осознаваемых реакций индивида на ситуации конфликта мнений в малой группе; были выявлены личностные факторы не только конформных, но и нонконформных тенденций в поведении испытуемых. Также интересными оказались результаты изучения роли разных видов (критериев) социометрического статуса как факторов континуума конформности.

Также важнейшей и актуальнейшей сегодня является проблема соотношения ситуационных и личностных факторов поведения человека. Её разрешением занимаются многие современные социальные психологи. Это, на наш взгляд, является перспективой для дальнейшего исследования.

Эмпирическое исследование, проведенное нами, во-первых, с помощью теста Кеттела HSPQ, показало по фактору E «подчиненность-доминантность», что большинство подростков проявляют конформное поведение, их можно охарактеризовать как уступчивых, зависимых от других, они стремятся раскрыться другим, в поведении корректны. И только 11,4 \% подростков по отношению к другим выступают как руководители, но это не коррелирует с истинным лидерством и реальными способностями. Они могут быть временными лидерами в экстремальных ситуациях или в неформальных группах. Они демократичны, им характерно высокое упорство в борьбе против норм, установок в группе, если что-то не устраивает. Склонны к самоутверждению, придерживаются своих взглядов, установок. Властны, авторитарны, ожидают самостоятельности от других.

По фактору Q2 (конформизм-нонконформизм) также большинство подростков - 34 человека $(88,6 \%)$ - зависимые, ведомые, идущие на зов, присоединяющиеся. Предпочитают принимать решения вместе с другими людьми. Любят процесс общения. Любят, когда ими восхищаются. Им не хватает решительности. Необходима поддержка группы. Близки к конформизму. 
Всего 2,8 \% подростков независимы, склонны идти своим путем, принимать собственные решения, действовать самостоятельно. Не считаются с общественным мнением. Не всегда доминируют. Нельзя сказать, что у них негативное отношение к другим людям, им просто не нужно их одобрение, поддержка. Предпочитают собственное мнение и решение. Плохо работают в группе, говорят, что при работе в группе теряют много времени. Причем этот один испытуемый женского пола - девочка. Таким образом, согласно результатам по обеим шкалам, большинство подростков зависимые, ведомые, то есть готовы проявлять конформное поведение.

Конформное поведение подростков было также измерено нами с помощью теста Т. Лири. По шкале «зависимость» большинству подростков (16 человек, что соответствует 45,7 \%) характерна умеренная степень выраженности зависимости, то есть они в основном конформные, мягкие, ожидают помощи и советов, доверчивые, склонные к восхищению окружающими, вежливые. Высокая степень выраженности зависимости свойственна четырем подросткам $(11,4 \%)$. Они послушны, боязливы, беспомощны, не умеют проявить сопротивление, искренне считают, что другие всегда правы. Экстремальной степени выявлено не было, то есть среди подростков не оказалось резко неуверенных в себе, имеющих навязчивые страхи, опасения, тех, которые тревожатся по любому поводу, поэтому зависимы от других, от чужого мнения.

Согласно результатам по шкале «дружелюбие», большинство подростков (13 человек / 37, 1\%) имеют высокую степень выраженности данного качества. То есть они чрезмерно дружелюбные и любезные со всеми, ориентированы на принятие и социальное одобрение, стремятся удовлетворить требования всех, "быть хорошими" для всех без учета ситуации, стремятся к целям микрогрупп, имеют развитые механизмы вытеснения и подавления, эмоционально лабильны. 12 подростков $(34,3 \%)$ имеют низкую и 10 подростков $(28,6 \%)$ умеренную степень «дружелюбия». Они склонны к сотрудничеству, кооперации, гибкие и компромиссные при решении проблем и в конфликтных ситуациях, стремятся быть в согласии с мнением окружающих, сознательно конформные, следуют условностям, правилам и принципам "хорошего тона" в отношениях с людьми, инициативные энтузиасты в достижении целей группы, стремятся помогать, чувствовать себя в центре внимания, заслужить признание и любовь, общительные, проявляют теплоту и дружелюбие в отношениях.

Диагностика индивидуально-психологических особенностей подростков по тесту Дж. Брунера (определение типа мышления и уровня креативности) показала, что у большинства подростков все показатели: предметное, символическое, знаковое мышление находятся на среднем уровне, а образное мышление, напротив, у большинства 17 человек (48,57 \%) - на высоком уровне. Креативность-творческость - тоже на среднем уровне. Если составить портрет наших испытуемых по базовому типу мышления и креативности и проранжировать их, то у них развито: 1) в большей степени образное мышление: подростки с художественным складом ума предпочитают образный тип мышления; 2) затем креативность: творческие способности человека, характеризующиеся готовностью к созданию принципиально новых идей; 3) 
симолическое мышление: подростки с математическим складом ума отдают предпочтение символическому мышлению, когда происходит преобразование информации с помощью правил вывода; 4) чуть в меньшей степени знаковое мышиление: личности с гуманитарным складом ума предпочитают знаковое мышление; 5) и последним по рангу идет предметное мышление: подростки с практическим складом ума предпочитают предметное мышление, для которого характерны неразрывная связь с предметом в пространстве и времени, осуществление преобразования информации с помощью предметных действий, последовательное выполнение операций.

Далее нами была проведена диагностика подростков по индивидуальнотипологическому опроснику (ИТО) Л.Н. Собчик. У большинства подростков показатели экстраверсии, спонтанность, агрессивность, ригидность, интроверсия, сензитивность, тревожность, лабильность находятся в пределах нормы. Таким образом, наши испытуемые подросткового возраста в большинстве своем гармонично развитые личности.

Влияние индивидуально-психологических особенностей личности на ее конформное поведение в подростковом возрасте вычислялось нами с помощью корреляционного анализа по Пирсону в программе Microsoft Excel. Для каждого показателя конформного поведения были выявлены комплексы индивидуальнопсихологических свойств подростков, чтобы доказать выдвинутую вначале гипотезу.

Мы получили на одном полюсе подростка конформного поведения с такими индивидуально-психологическими свойствами, как: повышенная тревожность, сензитивность, низкая спонтанность, низкая лабильность, высокая экстраверсия, высокая ригидность, развитое предметное, знаковое, символическое мышление.

На другом полюсе мы видим неконформного, независимого подростка с другим комплексом индивидуально-психологических особенностей: высокий уровень интроверсии, спонтанность, низкая тревожность; низкая сензитивность, высокая лабильность, низкая экстраверсия, низкая ригидность.

Как видим, гипотеза о том, что индивидуально-психологические особенности личности влияют на конформное/неконформное поведение в подростковом возрасте подтвердилась, и если конформное поведение закрепляется, становится устойчивым качеством личности, оно рассматривается как отрицательное качество, мешающее личности развиваться в самостоятельную, независимую личность. По словам Р. Кратчфилда, нонконформист способен успешнее сопротивляться давлению группы, если обладает достаточно высоким уровнем умственного развития и творческими способностями, проявляет терпимость и, кроме того, верит в себя и устойчив к стрессу. Чаще всего именно благодаря таким людям, осуществляются нововведения и действуют силы общественного преобразования.

\section{Литература}

1. Макарова И.Н. Индивидуально-стилевые детерминанты психических репрезентаций масштабных международных событий // Гуманитарный вектор. 2012. № 1. С. 211-217. 
2. Макарова И.Н. Индивидуально-психологические особенности личности как фактор межличностных отношений в волонтерских объединениях // Олимпийский Сочи: Социум. Культура. Личность: Материалы 5-й Всерос. науч.-практ. конф., г. Сочи, 4-6 октября 2012 г. / Отв. ред. И.Н. Макарова, Е.В. Поступинская. - Сочи: РИЦ СГУ, 2012. С.12-28.

\section{ОСОБЕННОСТИ ПСИХОЛОГИЧЕСКОЙ АДАПТАЦИИ МОЛОДЕЖИ ВО ВРЕМЯ ПРОФИЛЬНОЙ СМЕНЫ (НА ПРИМЕРЕ СМОЛЕНСКИХ ОБЛАСТНЫХ СБОРОВ ТВОРЧЕСКОЙ МОЛОДЕЖИ) \\ Сидоренков, А.С., Морозикова И.В.}

Летний отдых важен для полноценного развития детей, и его содержанию и качеству следует уделять особое внимание. В это время ребенок имеет много свободного времени и возможность отдохнуть от напряженного учебного года и набраться сил для нового. Государство обязуется принимать меры по обеспечению максимальной доступности услуг организации отдыха детей и их оздоровления, что согласуется с Федеральным законом от 24.07.1998 N 124-Ф3 (ред. от 28.12.2016) «Об основных гарантиях прав ребенка в Российской Федерации» [8]. Одним из популярных видов детского отдыха является летний оздоровительный лагерь. За время, проведенное в нем, кроме физического оздоровления, дети набираются опыта общения с коллективом, раскрывают свои творческие способности и т.п. Сейчас в России организуется большое количество детских лагерей разного уровня (языковые и профильные лагеря, направленные на развитие лидерских качеств, творческих способностей и т.д.). И одной из главных проблем такого отдыха является то, что дети, попав в новые социальные условия (новый детский коллектив, коллектив вожатых) могут испытывать проблемы с адаптацией к этим новым условиям, особенно в первые дни пребывания. Понимание особенностей психологической адаптации молодежи во время организационного периода профильной смены требует изучения и определяет актуальность исследования.

В отечественной психологии изучением проблемы психологической адаптации детей занимались такие ученые, как Д.Н. Дубровин, А.В.Петровский, А.А.Реан, А.В.Морозов и др.

Так, Д.Н.Дубровин под психологической адаптацией, понимает единство и взаимодействие социальной и личностной адаптации к современной жизни [2]. А.А. Реан рассматривает социально-психологическую адаптацию как активное самоизменение личности в соответствии с требованиями ситуации [5]. В.М.Шепель считает, что адаптация - это процесс приспособления личности к социально-психологическим условиям среды [10].

Таким образом, под адаптацией можно рассматривать, процесс приспособления как внутренних функций организма к условиям внешней среды, так и личности индивида к социально-психологическим условиям среды. С этой точки зрения, психологическая адаптация - приспособление человека к 